\title{
Analisis dan Perancangan Sistem Informasi Pemetaan Kompetensi Pengajar LP3 STT-NF Berbasis Web Menggunakan Yii Framework
}

\author{
Nasrul \\ Teknik Informatika, Sekolah Tinggi Teknologi Terpadu Nurul Fikri \\ Jl. Lenteng Agung No. 20, Jakarta Selatan, 12640 \\ Email : nasrul@gmail.com \\ Desi Ratnasari \\ Teknik Informatika, Sekolah Tinggi Teknologi Terpadu Nurul Fikri \\ Jl. Lenteng Agung No. 20, Jakarta Selatan, 12640 \\ Email : desiratnasari866@gmail.com \\ Sirojul Munir \\ Teknik Informatika, Sekolah Tinggi Teknologi Terpadu Nurul Fikri \\ Jl. Lenteng Agung No. 20, Jakarta Selatan, 12640 \\ Email : rojulman@nurulfikri.co.id
}

\begin{abstract}
Abstrak
Seiring dengan perkembangnya teknologi yang begitu pesat dan banyaknya permintaan trainingtraining komputer, maka pemetaan kompetensi pengajar di sebuah lembaga kursus computer menjadi suatu keharusan, karena jika tidak, maka lembaga kursus tersebut akan mengalami kesulitan dalam melakukan penjadwalan mengajar sesuai dengan permintaan dari client. Lembaga Pendidikan dan Pengembangan Profesi Sekolah Tinggi Teknologi Nurul Fikri (LP3 STT-NF) yang berfokus pada kegiatan jasa training computer untuk pemerintahan, swasta dan masyrakat luas. Pada penelitian ini, penulis melakukan penelitian berupa pengembangan system informasi pemetaan komputensi pengajar LP3 STT-NF berbasis web menggunakan Yii Framework, diharapkan aplikasi dapat memenuhi kebutuhan organisasi LP3 STT-NF.
\end{abstract}

Kata Kunci: kompetensi pengjar, LP3 STT-NF, Yii Framework

\section{PENDAHULUAN}

LP3 STT-NF kepanjangan dari Lembaga Pendidikan dan Pengembangan Profesi Sekolah Tinggi Teknologi Terpadu Nurul Fikri merupakan sebuah lembaga yang memadukan antara pelatihan dan pendidikan di bidang Teknologi Informasi dan komunikasi.

LP3 STT-NF berdiri sejak tahun 1994 menjadi bagian dari Divisi pendidikan computer Yayasan Nurul Fikri. Sejak tahun 1998 sudah menyelenggarakan Pelaatihan Linux dan Open Source Pertama (Pelopor) di Indonesia dan menjadi independen sejak tahun 2000 dengan nama Lembaga Pendidikan Komputer (LPK) Nurul Fikri, kemudian berganti nama menjadi LP3 STT-NF hingga sekarang. Guna menguatkan eksistensi dan mengembangkan diri, kemudian mendirikan perusahaan sebagai paying korporasi dari pengembangan cabang pada tahun 2006 dengan nama PT Nurul Fikri Cipta Inovasi (NCI) dan sebagai konsekuensi dari layanan LP3 STT-NF dan PT NCI membentuk brand integrasi layanan "NF Computer" sebagai rumah Linux.

LP3 STT-NF meneyelenggarakan Pelatihan dan Pendidikan di bidang Teknologi Informasi dan Komunikasi dalam beberapa kategori produk yaitu:

- Public Class, merupakan short course bidang computer yang berbasis Linux maupun Windows.

- Exclusive Class, merupakan paket training yang diberikan kepada customer dengan durasi 6-8 jam perhari dengan jumlah peserta minimal 2 orang dan pelaksanaan pelatihannya di LP3 STT-NF.

- In House/In Company Training, yaitu pelatihan computer yang dikustomisasi untuk kebutuhan perusahaan-perusahaan swasta dan instansi-instansi pemerintahan.

Saat ini di LP3 STT-NF belum tersedianya system informasi pengelolaan data pengajar dan kompetensi pengajar. System yang berjalan saat ini berupa 
pencatatan secara manual data pengajar serta kompetensinya, menggunakan aplikasi Ms. Excel yang terkadang menyulitkan untuk pengolahan data pengajar yang masih menggunakan Ms.Excel dalam pengelolaannya dan belum menyatu dengan pengelolaan data pengajar dan kompetensinya.

Penelitian ini berupa pengembangan system informasi pemetaan kompetensi pengajar LP3 STT-NF berbasis web untuk dapat memenuhi kebutuhan organisasi LP3 STT-NF dalam pengelolaan data pengajar dan kompetensi yang dimilikinya. System informasi yang akan dikembangkan menggunakan Yii Framework, yang merupakan kerangka kerja pengembangan aplikasi web menggunakan bahasa pemrograman $P H P$.

\section{TEORI DASAR}

\subsection{Pengertian Kompetensi Pengajar}

Guru atau pengajar memiliki pengaruh luas dalam dunia pendidikan. Di lembaga pendidikan dia adalah pelaksana pendidikan yaitu bertanggung jawab agar pendidikan dapat berlangsung dengan baik. Pengajar wajib memiliki kualifikasi akademik, kompetensi, sertifikat pendidik, sehat jasmani dan rohani, serta memiliki kemampuan untuk mewujudkan tujuan pendidikan nasional [1].

Dr. H. Syaiful Sagala, M.Pd. berpendapat bahwa kompetensi adalah perpaduan dari penguasaaan, pengetahuan, keterampilan, nilai dan sikap yang direfleksikan dalam kebiasaan berpikir dan bertindak dalam melaksanakan tugas atau pekerjaannya [2].

Kompetensi guru menunjuk kepada performance dan perbuatan yang rasional untuk memenuhi spesifikasi tertentu dalam melaksanakan tugas-tugas kependidikan. Hal tersebut dikatakan rasional karena kompetensi mempunyai arah dan tujuan, sedangkan performance adalah perilaku nyata seseorang yang diamati oleh orang lain.

\subsection{Unified Process}

Menurut Carg Larman, Unified Process (UP) merupakan suatu metode pembangunan perangkat lunak yang menggunakan system objek oriented unified process. Unified Process menggunakan proses iterative pada projek yang menggunakan pendekatan desain dan analisa objek oriented (OOAD) [3].

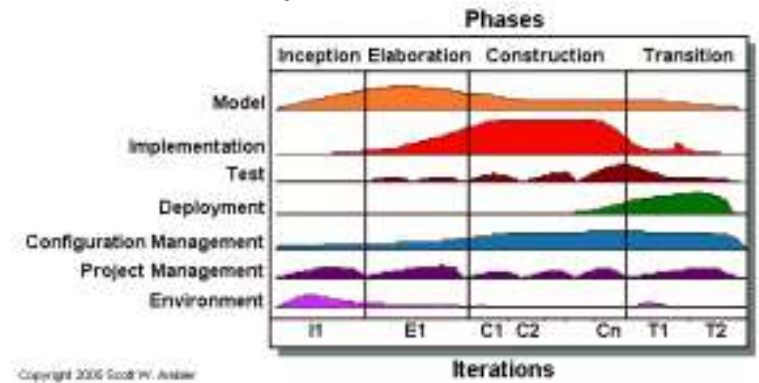

Gambar 1 Proses iterasi Unified Process
Dalam unified process terdapat beberapa fase yang dilakukan secara iterative [4], yaitu :

- Inception : fase awal menangkap visi yang diinginkan, memahami bisnis proses, menentukan skup pekerjaan, estimasi dan kelayakan dari proyek.

- Elaboration : fase mendefinisikan ulang visi yang diinginkan, iterasi implementasi arsitektur inti, menentukan faktur resiko proyek, identifikasi requirement utama dan skup pekerjaan, didapat waktu realistic pengerjaan proyek.

- Construction : pada fase dilakukan iterasi implementasi dan mengerjakan elemen tersisa yang beresiko rendah dan mudah, dilakukan proses persiapan deployment.

- Transition : fase testing dan transisi ke deployment.

UML (Unified Modellin language) merupakan alat bantu yang memiliki kemampuan handal di dalam pengembangan system yang berorientasi objek. Kehandalan UML ini dibuktikan dengan disediakannya bahasa pemodelan visual yang memungkinkan bagi pengembang system untuk membuat cetak biru atas visi mereka dalam bentuk baku, mudah dimengerti, dan dilengkapi dengan mekanisme yang efektif untuk berbagi serta mengkomunikasikan rancangan mereka dengan yang lain [4].

UML terbuat dari beberapa model yang menjelaskan bagaimana system dilakukan desain, model-model digambarkan dalam bentuk diagram-diagram : Use Case Diagram, Class Diagram, Object Diagram, Activity Diagram, Sequence Diagram, Colloboration Diagram, Statechart Diagram, Compoenent Diagram dan Deployment Diagram [3].

\subsection{Web Framework MVC}

Web Framework adalah kerangka kerja pengembangan aplikasi berbasis web. Web Framework digunakan oleh pengembang aplikasi untuk memudahkan pembangunan aplikasi yang dapat berupa sekumpulan library yang berisi fungsi, tools, ataupun class-class, dan digunakan sebagai kerangaka dalam pembangunan aplikasi.

Penggunaan web framework diharapkan membuat pengemabngan aplikasi menjadi rapidan bersih, memiliki struktur yang optimal, dan reusable. Struktur MVC digunakan untuk pemisahan antara business logic dengan presentation agar aplikasi menjadi tersetruktur, rapid an teratur.

Model View Controller merupakan konsep dalam pembangunan aplikasi web, berawal pada bahasa pemrograman Small Talk, MVC memisahkan pengembangan aplikasi berdasarkan komponen utama yang membangun sebuah aplikasi seperti manipulasi 
data, user interface, dan bagian yang menjadi control aplikasi.

Pola desain Model View Controller (MVC) terdiri atas 3 jenis objek, Model adalah objek aplikasi, View adalah objek antar muka tampilan presentasi dan Controller adalah bagaimana reaksi pengguna saat menerima inputan[5].

Beberpa manfaat dari pola desain MVC adalah : perubahan kode program oleh user dapat dilakukan tanpa mempengaruhi yang lain, seorang desainer dapat bekerja pada antarmuka tanpa khawatir tentang penyimpanan dan pengelolaan data, bagi pengembang dapat memprogram penanganan logika tanpa masuk kedalam rincian presentasi [6].

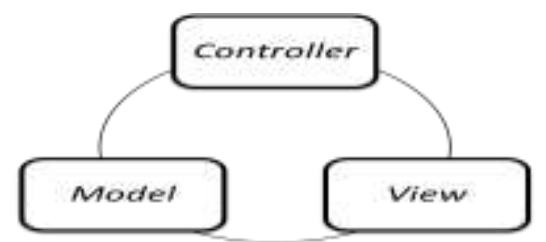

Gambar 2 Konsep MVC

\subsection{Yii Framework}

Yii Framework adalah kerangka kerja bahasa pemrograman web PHP berbasis komponen dengan performansi tinggi untuk pengembangan aplikasi web bersekala besar.

Yii sangat ringan digunakan dan dilengkapi dengan solusi caching yang memuaskan untuk pengembangan aplikasi dengan lalu lintas-tinggi, seperti portal, forum, system manajemen konten (CMS), system e-commerce dan lain-lain [7].

Yii Framework saat ini mempunyai dua versi utama : 1.1 dan 2.0 versi 1.0 adalah generasi lama. Versi 2.0 adalah penulisan ulang lengkap dari yii framework. Mengadopsi teknologi terbari dan protocol, termasuk composer, PSR, namespace, trait dan sebagainnya. Versi 2.0 merupakan generasi sekarang dari Yii Framework.

\subsection{Black Box Testing}

Black-box testing merupakan pendekatan pengujian yang ujinya diturunkan dari spesifikasi program atau komponen. System merupakan "Kotak Hitam" yang perilakunya hanya dapat ditentukan dengan mempelajari input dan output uang berkaitan. Metode black-box ini tidak seperti white box yang dapat dilakukan di awal tetapi pengujian black-box dilakukan pada tahap akhir, artinya sebelum program secara keseluruhan selesai program dapat diuji dengan metode white-box untuk menguji control structure dari sebuah program sedangkan black-box mengabaikan control structure dan lebih berfokus pada domain informasi apakah input yang diberikan penguji menghasilkan keluaran yang diharapkan oleh user. Pada pengujian black-box kesalahan yang berusaha ditemukan antara lain [8]:

- Kesalahan Performa

- Kesalahan interface

- Kesalahan dalam struktur data atau akses database eksternal

- Fungsi-fungsi yang salah atau hilang

Salah satu metode balck-box testing yaitu equivalence class partitioning, equivalence class partitioning adalah metode uji coba black-box yang membagi domain inout dari program menjadi beberaoa kelas data dari kasus uji coba yang dihasilkan. Equivalance class partitioning berusaha untuk mendefinisikan kasus uji agar dapat menemukan sejumlah kesalahan, kasus uji yang didesain untuk equivalence class partitioning berdasarkan pada evaluasi dari ekuivalensi jenis atau class untuk kondisi input. Class-class yang ekuivales merepresentasikan sekumpulan keadaan valid dan invalid untuk kondisi input. Kondisi input sendiri dapat berupa nilai numeric yang spesifik, kisaran nilai (range), sekumpulan nilai yang berhubungan (himpunan0, atau kondisi Boolean [8].

\section{METODE PENELITIAN}

Penelitian ini dilakukan dengan menggunakan tahapan metode :

A. Tahapan Penelitian

Metode pengembangan rekayasa perangkat lunak yang digunkan yaitu unified process. Metode ini menekankan pada use case dan pendekatan iterative untuk siklus pengembangan perangkat lunak dan aktifitasnya berfokus pada pengembangan model yang menggunakan UML, untuk mudah melakukan perbaikan berulang-ulang hingga sesuai kebutuhan user yang bisa di lihat pada gambar 3 .

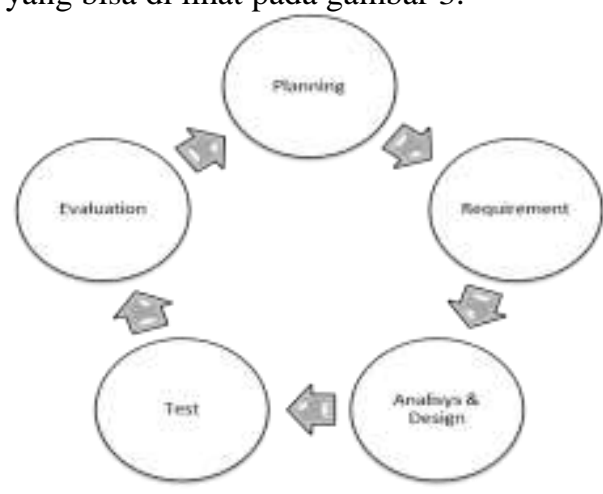

Gambar 3 Tahapan Unified Process

Ada empat fase yang terdapat dalam unified process, berikut penjelasannya [20]:

1. Fase Inception

a. Melakukan komunikasi (Communication)

i. Berkolaborasi dengan stakeholders

ii. Mengidentifikasikan kebutuhan bisnis, yaitu:

- Menentukan batasan-batasan dalam 
proyek. Anggaran dan biaya proyek.

- Menentukan tipe model yang akan dipakai dalam proses pengembangan software itu sendiri.

- Mendeskripsikan persiapan untuk use case yang akan dibuat.

\section{b. Perencanaan (Planning)}

Merencanakan model proyek yang iterative dan incremental, seperti mengidentifikasi sumber, resiko-resiko yang mungkin terjadi, membuat jadwal proyek.

\section{Fase Elaboration}

a. Planning

i. Menganalisa problem, memastikan kembali skup proyek.

ii. Mengembangkan perencanaan project.

iii. Menghilangkan kemungkinan munculnya resiko dalam proses perkembangan project itu sendiri, dikarenakan jika sampai terjadi perubahan terhadap project dalam fase berikutnya, akan menyulitkan pengembang project tersebut untuk kembali meninjau ulang.

\section{b. Modeling}

Pengimplementasian use case, sebagai perwujudan dari arsitektur system software.

3. Fase Construction

a. Membuat kode (Architectural model : operational use-cases)

i. Pendefinisian kebutuhan dan disain model harus sudah selesai. Versi final dari software increment.

ii. Semua fungsi dan fitur diimplementasikan ke dalam source code.

b. Testing

i. Unit tes didisain dan dijalankan.

ii. Use-case digunakan saat tes untuk melihat kesesuaian hasil software dengan use-case.

\section{Fase Transition}

\section{a. Testing}

Beta testing, yaitu testing yang dilakukan pihak end user setelah software di install di perusahaan.

b. Deployment

Membuat dokumentasi pendukung (contoh: user manual, panduan instalasi, dan lainlain).

c. End of transition phase

Yaitu pada saat software sudah siap untuk di release.

\section{B. Metode Pengembangan}

Metode pengembangan pada penelitian menggunakan metode unified process, metode unified process ini memiliki tahapan-tahapan utama di setiap fasenya (core workflow)

Gambar 4 Rancangan Analisis antara lain:

1. Requirement

Tujuan dari requirement adalah untuk menemukan dan mencapai persetujuan mengenai yang dilakukan system yang di ungkapkan dalam bahasa user. Selanjutnya requirement akan digambarkan dalam istilah use case, sehingga outputnya berupa use case model yang terdiri atas use case, actor, GUI prototype, dan nonfunctional requirement.

2. Analysis

Analisis bertujuan untuk menerjemahkan requirement ke dalam bahasa developer dan mengindetifikasi elemen atau entitas utama dari system yang diperlukan untuk memenuhi user requirement.

3. Design

Design untuk menspesifikasi secara penuh bagaimana fungsionalitas akan di implementasikan dengan menggunakan model yang telah dihasilkan dari workflow analisis

4. Implementation

Implemntasi untuk mentransformasukan design model ke dalam executable code, source code program dibuat pada workflow ini.

5. Testing

Tujuan dari pengujian untuk memastikan bahwa system dapat menyediakan fungsionalitas yang di perlukan. Pada tahapan ini, dilakukan proses pengujian oleh pengguna dengan mengisi form user acceptance test (UAT).

C. Rancangan Analisis

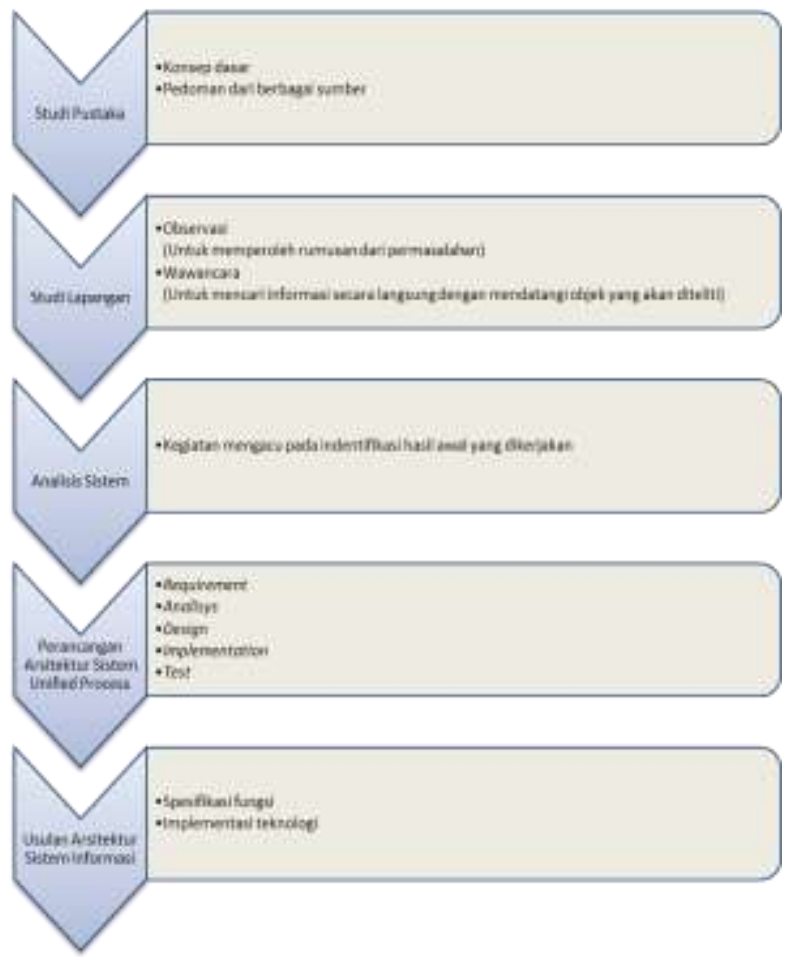


Rancangan analisis berguna untuk mencapai tujuan yang telah direncanakan dari mulai studi pustaka sampai tahap akhir penelitian.

\section{PEMBAHASAN DAN ANALISIS}

\subsection{Perancangan Sistem}

A. Analisis System

Pada penelitian ini dilakukan proses pengumpulan requirement user dengan melakukan proses wawancara dengan beberapa orang di divisi pembelajaran LP3 STT NF untuk mengetahui kebutuhan apa saja yang diperlukan untuk pengembangan aplikasi pemetaan pengajaran.

- Use Case

Pada penelitian ini dilakukan proses pengumpulan requirement user dengan melakukan proses wawancara dengan beberapa orang di divisi pembelajaran LP3 STT NF untuk mengetahui kebutuhan apa saja yang diperlukan untuk pengembangan aplikasi pemetaan pengajaran.

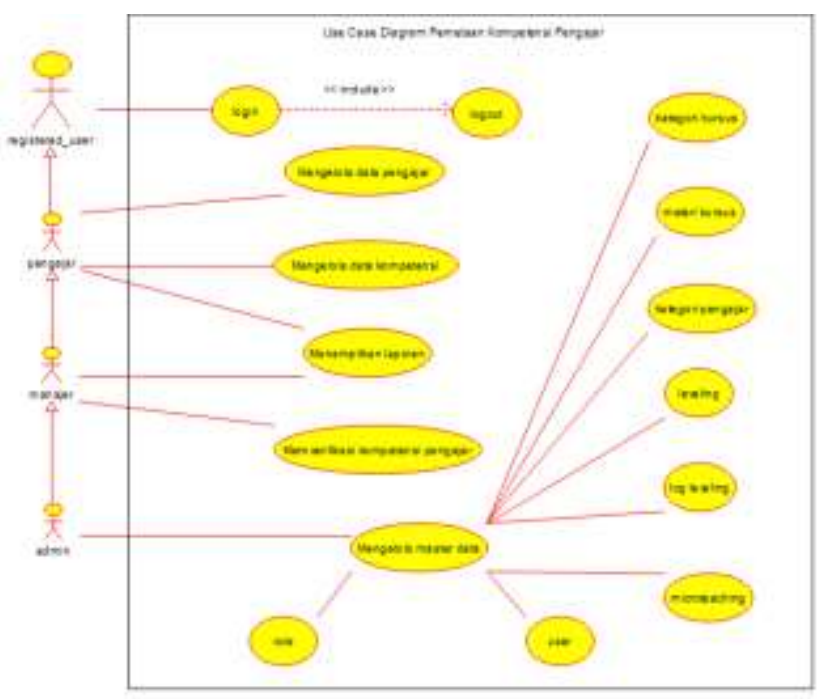

Gambar 5 Use Case Diagram Kompetensi Pengajar

Dari diagram use case pada Gambar 4.1 dapat dijelaskan bahwa untuk memasuki halaman backend aplikasi, user harus login dengan account user yang telah terdaftar di sistem. User pengajar dapat mengelola datanya dan peningkatan kompetensinya. Manajer dapat melihat laporan dan memverifikasi kompetensi pengajar. Untuk user admin bertugas untuk mengelola master data : kategori kursus, materi kursus, kategori pengajar, leveling pengajar, microteaching, mengelola user dan role.

B. Desain system

Desain system yang dibuat dalam penelitian ini antara lain domain model, sequence diagram, collaboration diagram, dan class diagram. Jika pada proses pembuatan use case diagram dan use case scenario dibuat berdasarkan pandangan user, sekarang masuk pada tahap pengembangan desain lebih lanjut lagi dengan sudut pandang sistem.

- Domain model untuk menunjukan hubungan yang mungkin ada di antara objek-objek yang sangat kompleks, secara umum objek diagram berisi dengan objek dan link.

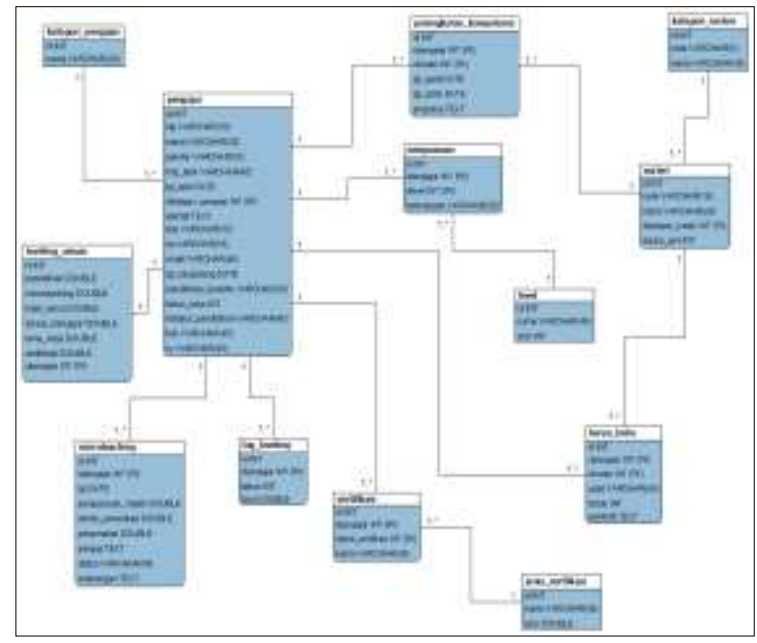

Gambar 6 Domain Model Pemetaan Kompetensi Pengajar

- Sequence System Diagram untuk menggambarkan perilaku pada scenario yang telah dibuat. Jika pada use case scenario tidak dideskripsikan objek-objek apa saja yang terlibat dalam sistem, maka pada sequence diagram bisa terlihat objek-objek apa saja yang terlibat dalam skenario yang telah dibuat. 


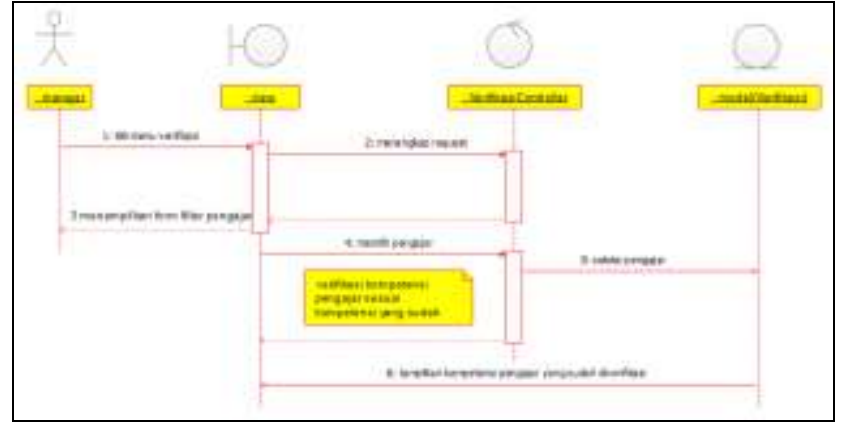

Gambar 7 Sequence Diagram Verifikasi Kompetensi Pengajar

Pada Gambar 7, dapat dijelaskan bahwa seorang user manajer untuk memverifikasi kompetensi pengajar merequest halaman verifikasi, lalu setelah itu manajer memilih pengajar untuk diverifikasi kompetensinya berdasarkan kompetensi materi bahan ajar yang sudah diinput oleh pengajar yang bersangkutan.

- Collobration Diagram

Collobration Diagra merupkan perluasan dari objek diagram, collaboration diagram menunjukan messege-messege objek yang dikirimkan satu sama lain.

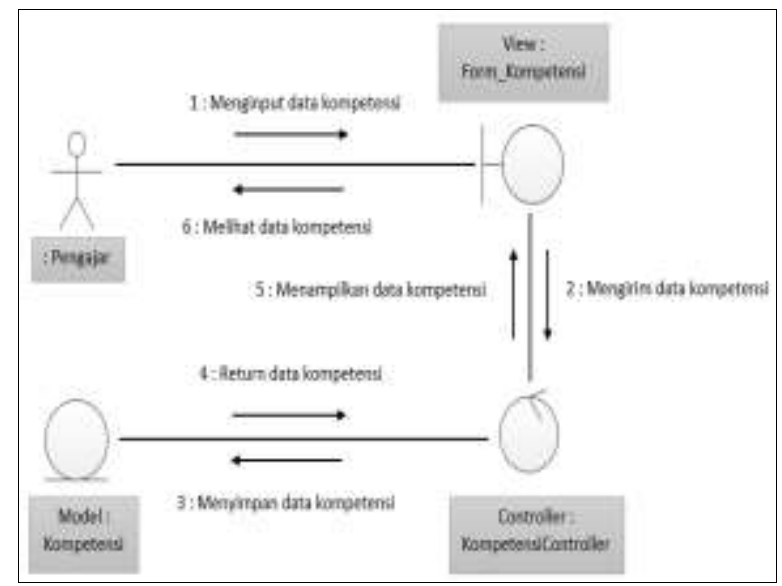

\section{Gambar 8 Collobaration Diagram Kompetensi Pengajar}

Pada Gambar 8 menggambarkan tentang proses pengelolaan data kompetensi pengajar.

- Class Diagram

Class Diagram merupakan bagian dari domain model, pada class diagram yang dilengkapi dengan operasi-operasi standar yang akan dilakukan pada tiap objek.

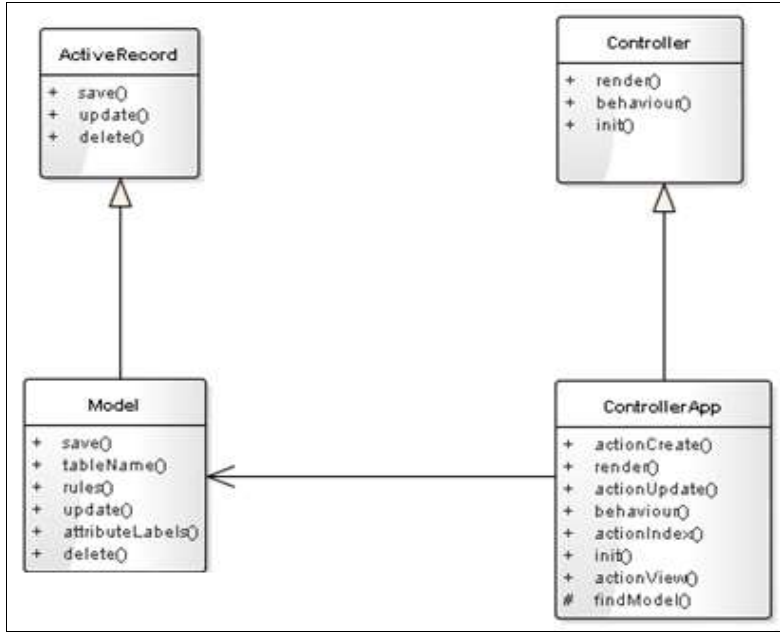

Gambar 9 Class Diagram MVC

Pada Gambar 9. Class diagram pemetaan kompetensi pengajar, dapat disimpulkan bahwa masing-masing model memiliki method-method yang sama terkait CRUD Application. Method-method yang melekat pada model-model di atas, merupakan hasil generate dari tool gii yang ada pada Yii Framework. Fungsi-fungsi tersebut diantaranya adalah :

- $\quad$ Create() : untuk menyimpan data

- Update(): untuk mengubah data

- Delete() : untuk menghapus data

- $\quad \operatorname{Admin}()$ : untuk mengelola data

- View() : untuk melihat data

- Index() : untuk melihat halaman utama

\subsection{Prototype Aplikasi}

Hasil prototype Perancangan Sistem Informasi Pemetaan Kompetensi Pengajar LP3 STT-NF Berbasis Web Menggunakan Yii Framework yang telah di implementasi dijelaskan dalam sebuah table yang berisikan pemetaan antara tujuan pengembangan system dengan use case, pengujian dilakukan dengan metode black-box testing.

Dalam penelitian kali ini penulis mengambil tipe dari Black Box Testing adalah Equivalence Class Testing dengan kriteria sebagai berikut [22] :

- Bagi domain input ke dalam beberapa kelas yang nantinya akan dijadikan sebagai kasus uji.

- Kelas yang telah terbentuk disajikan sebagai kondisi input dalam kasus uji.

- Kelas tersebut merupakan himpunan nilainilai yang valid dan tidak valid.

- Kondisi input bisa merupakan suatu range, harga khusus, suatu himpunan, atau suatu boolean.

- Bila kondisi input berupa suatu range, maka input kasus ujinya satu valid dan dua yang invalid. 
- Bila kondisi input berupa suatu harga khusus, maka input kasus ujinya satu valid dan dua yang invalid.

- Bila kondisi input berupa suatu anggota himpunan, maka input kasus ujinya satu valid dan dua yang invalid.

- Bila kondisi input berupa suatu anggota boolean, maka input kasus ujinya satu valid dan dua yang invalid.

Berikut contoh tampilan aplikasi Sistem Informasi Pemetaan Kompetensi Pengajar LP3 STT-NF.

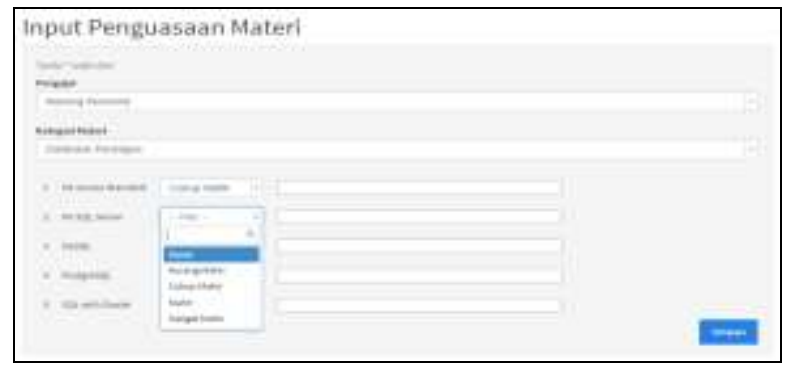

Gambar 10 Form Kompetensi Pengajar

Pada Gambar 10 merupakan halaman input kompetensi pengajar. Untuk isi form ini didahului dengan memilih pengajar dan kategori materi kursus, setelah itu barulah ditampilkan materi kursus berdasarkan kategori materi yang dipilih. Masing-masing materi kursus memiliki tingkatan level penguasaan dari mulai dasar sampai sangat mahir.

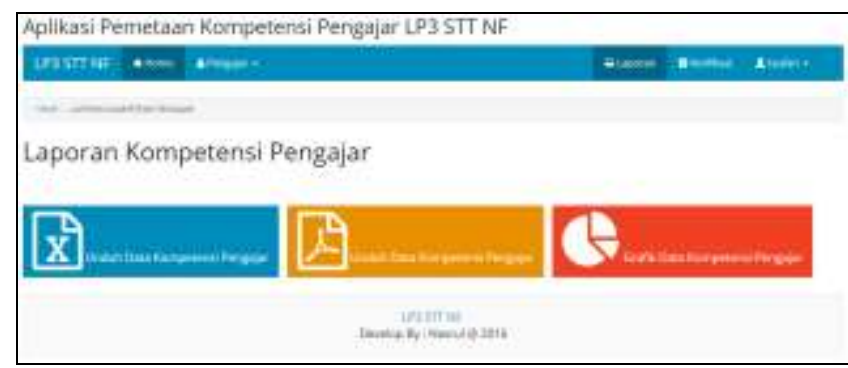

Gambar 11 Halaman Laporan

Pada Gambar 11 merupakan halaman seluruh laporan yang hanya dapat diakses oleh user manajer. Di dalam halaman ini, user manajer dapat melihat seluruh laporan data kompetensi pengajar yang dapat dilihat ke dalam tiga bentuk laporan yaitu :

- Laporan dalam bentuk Ms. Excel

- Laporan dalam bentuk PDF

- Laporan dalam bentuk grafik

\section{KESIMPULAN}

Pada penelitian ini dapat disimpulkan bahwa pengembangan aplikasi pemetaan kompetensi pengajar LP3 STT-NF berbasis web dengan menggunakan Yii
Framework, Aplikasi pemetaan kompetensi pengajar LP3 STT-NF setelah dilakukan pengujian (User Acceptance Test) sudah sesuai dan memenuhi kebutuhan organisasi untuk memetakan kompetensi pengajar yang ada. Serta aplikasi pemetaan kompetensi pengajar LP3 STT-NF dapat diakses via jaringan internet dengan menggunakan browser dan dapat responsive terhadap platform mobile dan desktop serta platform-platform yang lainnya.

\section{DAFTAR PUSTAKA}

[1] Drs. Zainal Asril, M.Pd, "MICROTEACHING”, (Jakarta: Rajawali Pers, 2010), h. 9.

[2] Dr. H. Syaiful Sagala. "KEMAMPUAN PROFESSIONAL GURU DAN TENAGA KEPENDIDIKAN". (Bandung: Alfabeta, 2009) h. 29.

[3] Carg Larman, "Applying UML And Patterns", Prentice Hall, 2004.

[4] M. Pemodelan Visual Dengan UML, Yogyakarta: Graha Ilmu, 2005.

[5] Erich Gamma, John Vlissides, Ralph Johnson, and Richard Helm " Design Pattern Elements of Reusable Object-Oriented Software", Addison Wesley, 2000

[6] Ayman Hourieh, "Learning Website Development with Django", Packt Publishing, Birminghammumbai 2008.

[7] http://www.yiiframework.com/doc-2.0/guideREADME.html (diakses pada tanggal 3 Januari 2016)

[8] R. S. Pressman, "Software Enginnering," in APRACTITIONER'SAPPROACH, New York, McGraw-Hill, 2001, p. 36.

[9] Ethan Marcotte, "RESPONSIVE WEB DESIGN (BRIEF BOOKS FOR PEOPLE WHO MAKE WEBSITES, No. 4)", Paperback, 2011.

[10] R. M. R. Attamimi, "PEMBANGUNAN SISTEM INFORMASI MANAJEMEN INVENTARISASI BARANG MILIK NEGARA DENGAN METODE AGILE UNIFIED PROCESS (AUP)," IPB, Bogor, 2013.

[11] M. IQBAL TANJUNG, "ANALISIS DAN PERANCANGAN SISTEM INFORMASI BERBASIS WEBSITE MENGGUNAKAN ARSITEKTUR MVC DENGAN FRAMEWORK CODEIGNITER Studi Kasus : Ikatan Pelajar Mahasiswa Kepulauan Riau Yogyakarta”, AMIKOM, Yogyakarta, 2011.

[12] M. Toha, "IMPLEMENTASI FRAMEWORK SPRING MVC UNTUK PEMBUATAN SISTEM INFORMASI MANAJEMEN E-COMMERCE," Universitas Sebelas Maret, Surakarta, 2010. 
ISSN 2477-0043

Jurnal Teknologi Terpadu

e-ISSN 2460-7908

Vol. 2, No. 2, Desember, 2016

[13] Stanley Karouw, "ANALISA DAN PERANCANGAN APLIKASI DORMITORY

MANAGEMENT MENGGUNAKAN UNIFIED

SOFTWARE DEVELOPMENT PROCESS",

Universitas Sam Ratulangi, 2012. 